\title{
Axoplasmic Flow of Tritiated Proline in the Corticospinal Tract of the Rat
}

\author{
H. Lee Vahlsing, Ronald B. Hirschl, and Earl R. Feringa* \\ Departments of Neurology and Pathology of the Ann Arbor Veterans Administration and University of \\ Michigan Medical Centers, Ann Arbor, MI, USA; and San Diego Veterans Administration Medical \\ Center and University of California, San Diego, San Diego, CA, USA
}

\begin{abstract}
Summary. The rates of axoplasmic transport were studied in the corticospinal tract of the rat by injecting tritiated proline into the sensory-motor cortex and subsequently analyzing the distribution of incorporated label in the spinal cord at intervals after injection. A mathematical model of the anatomy of the corticospinal tract was developed and used in analysis of the data. The rate of a fast component was calculated to be $240-420 \mathrm{~mm}$ per day, which is comparable with rates of fast components in the peripheral nervous system (PNS), but considerably greater than rates in other tracts in the central nervous system. A slow component was calculated to have a transport rate of $3-8 \mathrm{~mm}$ per day which is greater than rates found either in the CNS or PNS. This higher rate may be related to the greater length of the corticospinal tract as compared to other CNS tracts studied.
\end{abstract}

Key words: Axoplasmic flow - Corticospinal tract - Tritiated proline - Rats.

Although the rates of axonal transport of amino acids in the peripheral nervous system (PNS) have been studied in many different nerves (Gross and Beidler 1975a; Lasek 1968; Ochs and Ranish 1969), the transport rates in the central nervous system (CNS) have been studied primarily in the optic tract (Grafstein and Laureno 1973; Neale et al. 1974; Schlichter and McClure 1974). Most other CNS tracts have proven too short, too inaccessible, or anatomically too complex to lend themselves to transport rate studies. In particular, the corticospinal tract of the rat, while neither short nor inaccessible, is anatomically complex. Any attempt to study

Send offprint requests to: Earl R. Feringa, M.D., Chief, Neurology Service (127), Veterans Administration Medical Center, 3350 La Jolla Village Drive, San Diego, California, 92161, USA

* This research was financed by the Veterans Administration research support awarded to Dr. Feringa by the Development Funds of the Department of Pathology, University of Michigan, and by the University of Michigan Medical Center Fund for Computing. The authors wish to express their appreciation to Ms. Linda Lee Austin for technical assistance, Ms. Diane Trakas and Ms. Barbara Reader for secretarial aid, and Mr. Richard Fritzler for assistance with graphics 
transport rates in this tract must take into account the fact that the number of transporting axons decreases cranio-caudally in a non-linear fashion.

We have devised a model of the corticospinal tract that describes its diminishing size and allows us to approximate the transport rates of tritiated proline down the tract.

\section{Materials and Methods}

Eleven-week-old albino isogeneic female rats, descended from Wistar stock, were used in this experiment. Under ether anesthesia, each rat was immoblized in a stereotactic device. A midline sagittal incision was made through the scalp. Using a dental drill with a ball-shaped bit, two hoies were drilied through the cranium at locations $3 \mathrm{~mm}$ caudal to the coronal suture and $3 \mathrm{~mm}$ on either side of the sagittal suture. The dura mater was not penetrated. These sites are directly above the areas of the cerebral cortex than contain the cell bodies of the fibers of the corticospinal tract in the rat (Hicks and D'Amato 1975). With the aid of an operating microscope and a micromanipulator, the tip of a short-beveled, 30gauge needle was lowered through one hole, penetrating the cerebral cortex to a depth of $1 \mathrm{~mm}$. Fifty $\mu \mathrm{Ci}$ of tritiated proline in $2.5 \mu$ lactate-Ringer's solution was injected slowly into the cortex. After $1 \mathrm{~min}$, the needle was withdrawn and a similar cortical injection made on the contralateral side.

Groups of 3 rats each were killed and formalin-perfused at intervals 1,2,4,6,8,16 and $24 \mathrm{~h}$ and 2, 4, $7,10,14,17,21$ and 30 days after injection. Groups of 5 rats each were perfused with formalin at intervals of 60 and 90 days after injection.

The complete spinal cord was removed, the dura mater peeled off, and the dorsal and ventral rootlets were removed. Beginning at the obex, the cord was cut into $5 \mathrm{~mm}$ long segments, yielding a total of 16-20 segments per cord. Each segments was individually weighed, solubilized and the relative concentration of tritium estimated with a scintillation counter.

\section{Results}

\section{Fast Component}

The disintergrations per minute (DPM) in the segments of spinal cord of rats sacrificed $1,2,4,6,8,16$ and $24 \mathrm{~h}$ after injection of tritiated proline in to the sensory motor cortex are represented in Fig. 1. Relatively small amounts of tritium are present in 1- and 2-h segments, but a $4 \mathrm{~h}$ a large peak of tritium is present in segments near the obex. At successive time intervals, this peak appear to broaden out and spread down the spinal cord. The shape and rate of low of this peak are obscured by the diminishing size of the corticospinal tract.

\section{Slow Component}

The DPM found in spinal cord segments of rats sacrificed 2, 4, 7, 10, 14, 17, 21 and 30 days after tritiated proline injection are represented in Fig. 2. Again, relatively small amounts of tritium, when compared to later DPM, are present in 2-and 4-day segments, but at 7 days a large peak of tritium, 10 times that of the fast component, is present in segments near the obex. This peak also appears to broaden out and spread down the spinal cord at successive time intervals. The shape and rate of flow of this peak are also obscured by the anatomical complexities of the spinal cord. 


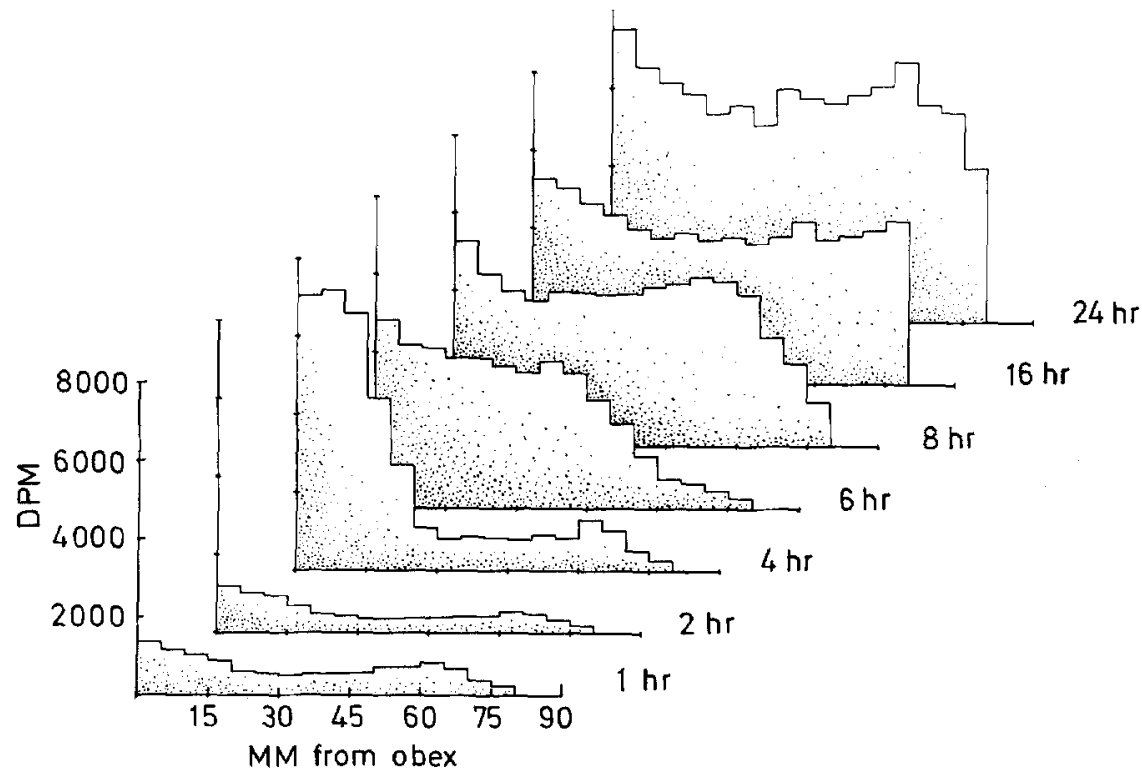

Fig. 1. Fast component. DPM found in spinal cord segments of rats sacrificed 1, 2, 4, 6, 8, 16 and $24 \mathrm{~h}$ after injection of $\left[{ }^{3} \mathrm{H}\right]$ proline into the sensory-motor cortex

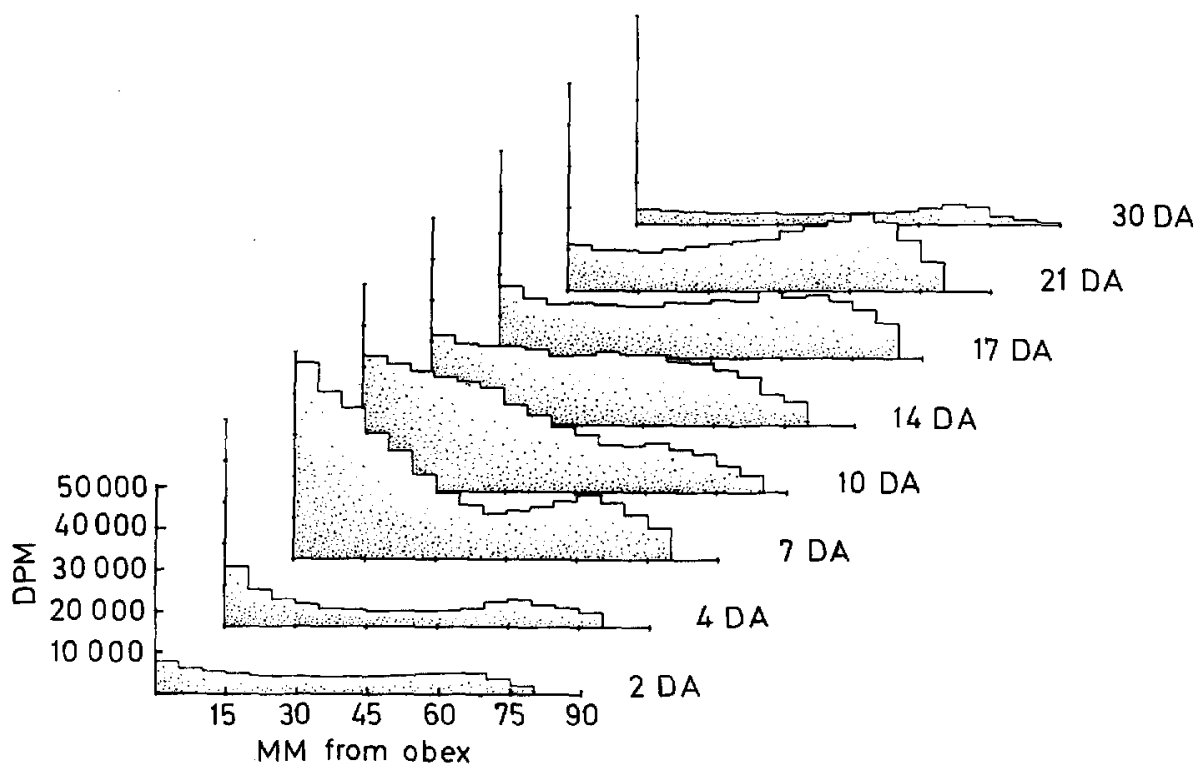

Fig. 2. Slow component. DPM found in spinal cord segments of rats sacrificed 2, 4, 7, 10, 14, 17, 21 and 30 days after injection of $\left[{ }^{3} \mathrm{H}\right]$ proline 


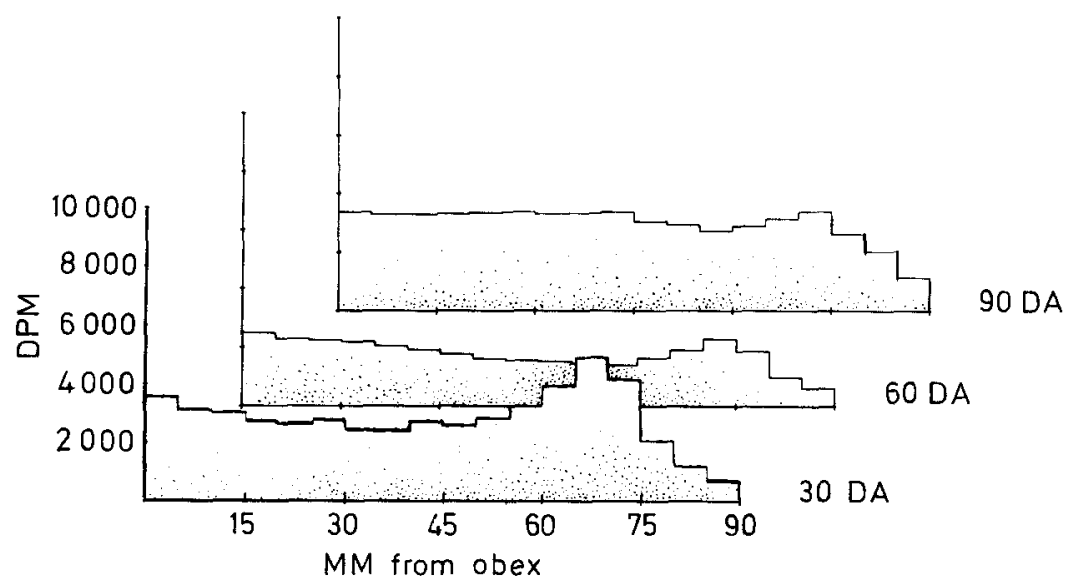

Fig. 3. Long-term labeling. DPM found in spinal cord segments 30,60 and 90 days after injection

\section{Long-Term Labeling}

The DPM found in spinal cord segments of rats sacrificed 30, 60 and 90 days after injection are represented in Fig. 3. By 30 days, tritium has completely traversed the length of the spinal cord and the residual label has begun to fade. The label continues to fade, but is still present at 60 and 90 days.

\section{Discussion}

\section{Adjustments Made for Background DPM}

It is clear from Fig. 1 that no significant wave of tritium activity is present in the spinal cord until $4 \mathrm{~h}$ after proline injection into the cortex. However, at 1 and $2 \mathrm{~h}$, tritium activity is about $50 \%$ higher than the usual background found in the spinal cord of uninjected control rats. This additional background is probably the result of diffusion of tritiated proline from the injection site within the blood, cerebrospinal fluid (CSF), and/or interstitial fluid. Strong support of this background theory was found when the DPM found in each segment of the 1- and 2-h rats were mathematically regressed against the mass, surface area, and inverse square of the distance from the injection site of that segment. (Blood-borne tritium should be proportional to the mass of the segment, CSF borne tritium should be proportional to the surface area of the segment, and passively diffused tritium in the interstitial fluid should be proportional to the inverse square of the distance from the injection site.) For each 1- and 2-h animal, this multiple linear regression yielded a correlation coefficient (Brownlee 1965) greater than 0.96. As a consequence, background counts similar to those found in spinal cord segments of 1 - and 2-h were subtracted from all other rat spinal-cord segments. These background counts were determined from the regression curves from the 1- and 2-h rats. 
Two days after injection with tritiated proline, the fast wave traversed the length of the spinal cord and left a residuum of tritium label in each segment which bears a high positive linear correlation with the mass of the segment $(r=0.94)$. This residuum was considered background to the oncoming slow wave. Consequently, DPM proportional to the mass of each segment were subtracted from the raw DPM to adjust for this source of background in rats from the 2-day and later groups.

\section{Adjustments Made for the Diminishing Size of the Tract}

The interpretation of scintillation counting data from segments of peripheral nerve or optic tract is relatively straightforward because the number of axons transporting label remains constant from segment to segment. However, a new complexity arises in the interpretation of the data from spinal cord segments due to the fact that the number of axons in the corticospinal tract decreases non-linearly, cranio-caudally. Neglecting background DPM momentarily, the DPM in each segment is the product of the amount of label present in each corticospinal axon and the number of corticospinal axons present in that segment. Therefore, in order to compare the various segments on the basis of the amount of tritium label per corticospinal axon, the DPM of each segment must be devided by the number of corticospinal axons present in that segment, or by the percent of the total corticospinal tract remaining in that segment.

To determine the percent of corticospinal tract present in each spinal cord segment, we first scanned cross-sectional autoradiograms of labeled spinal cord with a computer-linked microscope. The area of corticospinal tract was measured in each segment at both the proximal and distal ends (see Table 1). From these areas, we determined the pattern by which the corticospinal tract axons leave the tract and terminate in the dorsal horns along the length of the cord. Except for the very caudal segments, we found that the number of axons terminating within a segment bore a high positive linear correlation with the mass of that segment $(r=0.85)$. Therefore, from the masses of the spinal cord segments, we could approximate the pattern by which the corticospinal tract axons terminate and then estimate the percent of tract present in each segment.

\section{Transport Rates}

After subtracting background DPM from those of spinal cord segments, the remaining DPM found in each segment were divided by the percent of corticospinal tract present in that segment. The results of this calculation are represented in Fig. 4 for the fast wave and Fig. 5 for the slow wave.

It is apparent from Fig. 4 that the curves from 4-, 6-, and 8-h rats have well defined wave fronts and peaks and are appropriate for determination of the transport rate of the fast component. A rate of $420 \mathrm{~mm}$ per day is computed from either peak or wave front displacement during the 4- to 6-h interval. Similarly, a rate of $240 \mathrm{~mm}$ per day is calculated for the 6- to 8-h interval. This disparity in rates is in part the result of dividing the spinal cord into relatively long $(5 \mathrm{~mm})$ segments for 
Table 1. Data used to determine the correlation between mass and area of corticospinal tract within a spinal cord segment $(r=0.85)$

\begin{tabular}{|c|c|c|c|c|c|}
\hline \multirow[t]{2}{*}{$\begin{array}{l}\text { Segment } \\
\text { number }\end{array}$} & \multirow{2}{*}{$\begin{array}{l}\text { Tract area at } \\
\text { proximal end } \\
\text { of segment } \\
\left(\mathrm{mm}^{2}\right)\end{array}$} & \multirow{2}{*}{$\begin{array}{l}\text { Tract area at } \\
\text { distal end } \\
\text { of segment } \\
\left(\mathrm{mm}^{2}\right)\end{array}$} & \multicolumn{2}{|c|}{$\begin{array}{l}\text { Tract area } \\
\text { terminating } \\
\text { within segment }\end{array}$} & \multirow{2}{*}{$\begin{array}{l}\text { Weight } \\
\text { of } \\
\text { segment } \\
\text { (g) }\end{array}$} \\
\hline & & & $\left(\mathrm{mm}^{2}\right)$ & $(\%$ of total $)$ & \\
\hline 1 & 0.5408 & 0.4784 & 0.0624 & 11.5 & 2.52 \\
\hline 2 & 0.4784 & 0.3816 & 0.0968 & 17.9 & 2.04 \\
\hline 3 & 0.3816 & 0.3104 & 0.0712 & 13.2 & 2.09 \\
\hline 4 & 0.3104 & 0.2308 & 0.0796 & 14.7 & 2.07 \\
\hline 5 & 0.2308 & 0.1980 & 0.0328 & 6.1 & 1.81 \\
\hline 6 & 0.1980 & 0.1896 & 0.0084 & 1.5 & 1.30 \\
\hline 7 & 0.1896 & 0.1644 & 0.0252 & 4.7 & 1.20 \\
\hline 8 & 0.1644 & 0.1512 & 0.0132 & 2.2 & 1.23 \\
\hline 9 & 0.1512 & 0.1424 & 0.0088 & 1.6 & 1.08 \\
\hline 10 & 0.1424 & 0.1312 & 0.0112 & 2.0 & 0.98 \\
\hline 11 & 0.1312 & 0.1220 & 0.0092 & 1.7 & 1.14 \\
\hline 12 & 0.1220 & 0.1184 & 0.0036 & 0.7 & 1.12 \\
\hline 13 & 0.1184 & 0.1128 & 0.0056 & 1.0 & 1.30 \\
\hline 14 & 0.1128 & 0.0944 & 0.0184 & 3.4 & 1.36 \\
\hline 15 & 0.0944 & 0.0828 & 0.0116 & 2.1 & 1.65 \\
\hline 16 & 0.0828 & 0.0400 & 0.0428 & 7.8 & 1.82 \\
\hline 17 & 0.0400 & 0.0180 & 0.0220 & 4.1 & 1.05 \\
\hline 18 & 0.0180 & 0.0080 & 0.0100 & 1.8 & 0.56 \\
\hline 19 & 0.0080 & 0.0000 & 0.0080 & 1.5 & 0.36 \\
\hline
\end{tabular}

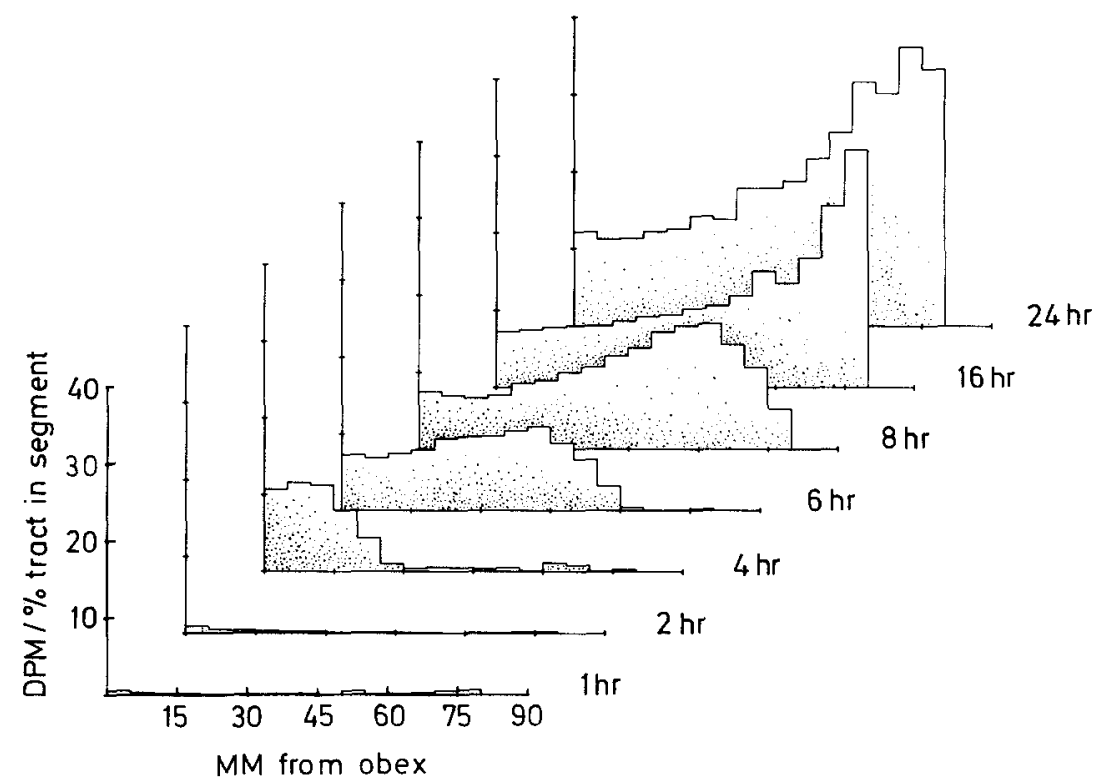

Fig. 4. Modified fast-component data. DPM in each segment have been adjusted by subtracting a background factor and dividing by the percent of corticospinal tract present in the segment 


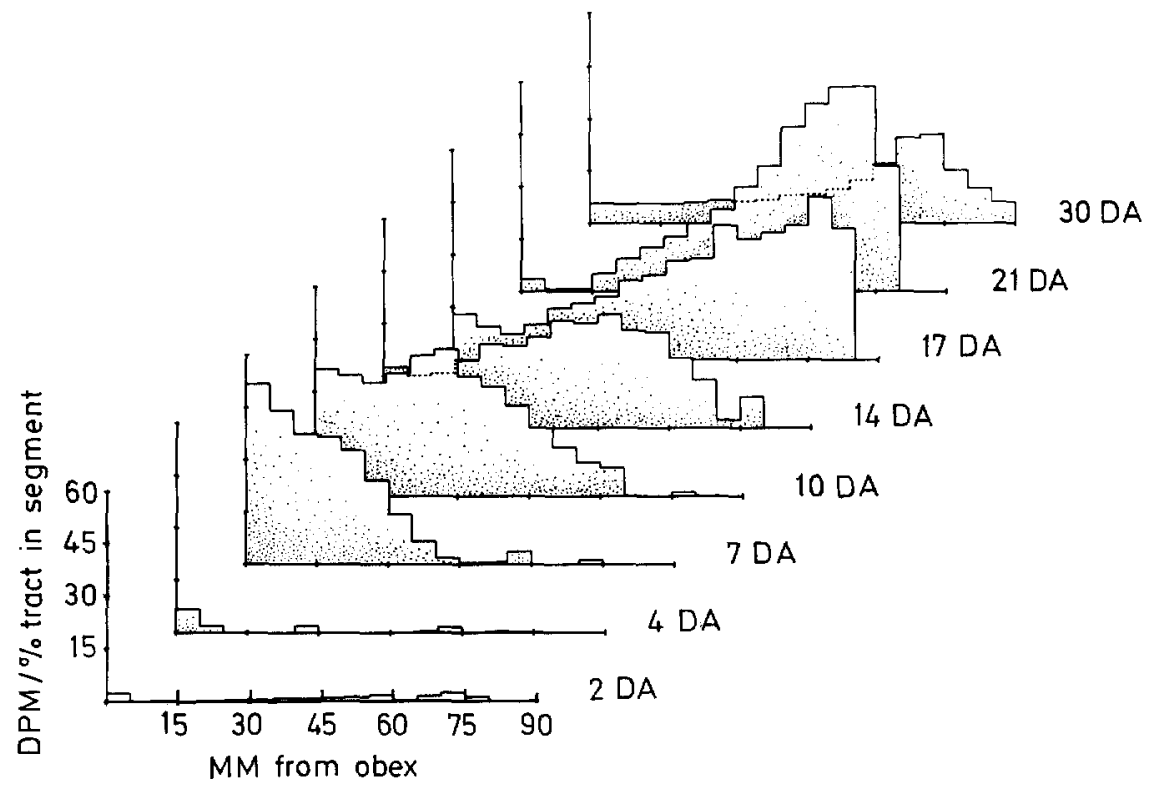

Fig. 5. Modified slow-component data. DPM in each segment have been adjusted for $\left[{ }^{3} \mathrm{H}\right]$ background and the percent of tract present in the segment

scintillation counting. The actual position of the tritium peaks could be determined only within the accuracy of $\pm 5 \mathrm{~mm}$. However, this uncertainty can explain only about $2 / 3$ ( $\pm 60 \mathrm{~mm}$ per day) of the disagreement in rats $(180 \mathrm{~mm}$ per day). This may indicate that the imposed mathematical corrections are flawed, or that the rate of the fast-transport component in the corticospinal tract varies with time or with the length of the axon. A variation in transport rate with axon length is not unknown (Murray 1974).

It is apparent from Fig. 5 that the curves from 7, 10 and 14 days have well defined wave fronts and peaks and are appropriate for determining the slowcomponent transport rate. Taking into account the uncertainty of the location $( \pm 5 \mathrm{~mm})$, a rate ranging from $3-8 \mathrm{~mm}$ per day is calculated.

In most cases, it was found that the adjustments made for tritium background were small in comparison to the magnitude of axonally transported tritium, so that the accuracy of the calculated rates was not heavily dependent on the accuracy or appropriateness of the background adjustments. The shape of the waves of transported tritium, however, is affected by these background adjustments, and the scintillation counting profiles must be viewed with this in mind.

The calculated rate of transport of amino acid in the fast component (240$420 \mathrm{~mm} /$ day) is consistent with the range of rates found in peripheral nerves of the rat (200-450 mm/day) (Bisby 1976; Fink et al. 1975, Komiya and Kurokawa 1978; Ochs 1972; Wood and Boegman 1975). However, this rate of flow is considerably greater than that reported by most authors for other CNS tracts in the rat. Transport of hormones by the hypothalamo-neurohypophysial tract has been reported as $48-96 \mathrm{~mm}$ per day (Pickering and Jones 1971). A fast-component flow 
of $50 \mathrm{~mm}$ per day was found for transport of $\left[{ }^{14} \mathrm{C}\right]$ leucine in the nigro-thalamic and nigro-striatal tracts (Fibiger et al. 1971). The first wave of $\left[{ }^{35} \mathrm{~S}\right]$ cysteine transported in the supraoptico-neurohypophysial tract occurs at $60 \mathrm{~mm}$ per day (Norström and Sjöstrand $1971 \mathrm{a}, \mathrm{b}$ ). Tritiated proline, DOPA and fucose are transported in central noradrenergic neurons from the locus ceruleus at a maximum rate of $96 \mathrm{~mm}$ per day (Jones et al. 1977; Levin 1977).

Using a very different technique which allows for the identification of the speed of transport of individual labeled polypeptides. Willard et al. (1974) identified a group of polypeptides which traversed the rabbit optic system from retina to lateral geniculate and superior colliculus at a rate of at least $240 \mathrm{~mm}$ per day. Their electrophoretic analysis of polypeptides labeled after intravitreous injection of $\left[{ }^{35} \mathrm{~S}\right]$ methionine clearly demonstrates a rate of at least $240 \mathrm{~mm}$ per day for these polypeptides, but gives no information as to the fraction of the injected protein that was transported at that rate. Their technique could easily identify a very small compartment not otherwise identifiable as a separate peak. Contrariwise, radioactive methionine may selectively label unique polypeptides in the rabbit retina which are transported at a very fast rate. If the latter is true, our data may indicate that intracorticaly injected tritiated proline labels similar fast-moving polypeptides.

The calculated rate of transport of amino acid by the slow component ( $3-8 \mathrm{~mm}$ per day) is somewhat higher than the rate found in peripheral nerves of the rat (1 mm per day) (Komiya and Kurokawa 1978) and that usually reported in rat CNS (.5-2.5 mm per day) (Fibiger et al. 1972; Norström and Sjöstrand $1971 \mathrm{~b}$ ). However, the transport rate of this component may be dependent on the length of the axon (Murray 1974). In the case of the corticospinal tract, the transport rate may be relatively rapid because the distance to be traveled is great (on the average, $5 \mathrm{~cm}$ ).

Also, the axons of the corticospinal tract are not of one length since they terminate along the length of the spinal cord. If the rate of slow transport is indeed dependent on the length of the axon, the calculated rate must represent an average rate, dependent on the average length of the corticospinal axons.

Three of four separate waves of slow polypeptide transport with velocities from 0.7 to $68 \mathrm{~mm}$ per day have been described in the optic nerve of the rabbit (Willard et al. 1974; Willard and Hulebak 1977). Although our data was not analyzed in a way that would make it possible to identify each of these components, the fronts and peaks found do not support the concept of several slow component rates. It is quite possible that the differences between the rates that we found in the corticospinal tract and the results of others relate to the slow component that is being measured. Perhaps in our animals tritiated proline labels mainly polypeptide 35 of Willard et al. (1974). A more detailed analysis of the particular polypeptides labeled with tritiated proline would be required to clarify this point.

\section{References}

Bisby MA (1976) Orthograde and retrograde axonal transport of labeled proteins in motoneurons. Exp Neurol 50:628-640 
Brownlee KA (1965) Statistical Theory and Methodology in Science and Engineering. Wiley Publications, New York

Fibiger HC, Pudritz RE, McGeer PL, McGeer EG (1972) Axonal transport in nigro-striatal and nigrothalamic neurons: effects of medial forebrain bundle lesions and 6-hydroxy dopamine. J Neurochem 19:1697-1708

Fink BR, Kish SJ, Byers MR (1975) Rapid axonal transport in trigeminal nerve of rat. Brain Res 90:8595

Grafstein B, Laureno R (1973) Transport of radioactivity from eye to visual cortex in the mouse. Exp Neurol 39:44-57

Gross GW, Beidler LM (1975a) A quantitative analysis of isotope concentration profiles and rapid transport velocities in the C-fibers of the garfish olfactory nerve. J Neurobiol 6:213-232

Hicks SP, D'Amato CJ (1975) Motor-sensory cortex-corticospinal system and developing locomotion and placing in rats. Am J Anat 143:1-42

Jones BE, Halaris AE, Mclihany M, Moore RY (1977) Ascending projections of the locus coeruleus in the rat. I. axonal transport in central noradrenaline neurons. Brain Res 127:1-21

Komiya Y, Kurokawa M (1978) Asymmetry of protein transport in two branches of bifurcating axons. Brain Res 139:354-358

Lasek RJ (1968) Axoplasmic transport of labeled proteins in rat ventral motoneurons. Exp Neurol $21: 41-51$

Levin BE (1977) Axonal transport of $\left[{ }^{3} \mathrm{H}\right]$ fucosyl glycoproteins in noradrenergic neurons in the rat brain. Brain Res 130:421-432

Murray M (1974) Axonal transport in the asymmetric optic axons of flatfish. Exp Neurol 42:636-646

Neale JH, Elam JS, Neale EA, Agranoff BW (1974) Axonal transport and turnover of proline- and leucine-labeled protein in the goldfish visual system. J Neurochem 23:1045-1055

Norström A, Sjöstrand J (1971 a) Axonal transport of proteins in the hypothalamo-neurohypophysial system of the rat. J Neurochem 18:29-39

Norström A, Sjöstrand J (1971 b) Transport and turnover of neurohypophysial proteins of the rat. J Neurochem 18:2007-2016

Ochs S (1972) Rate of fast axoplasmic transport in mammalian nerve fibers. J Physiol 227:627-645

Ochs S, Ranish N (1969) Characteristics of the fast transport system in mammalian nerve fibers. J Neurobiol 2:247-261

Pickering BT, Jones CW (1971) The biosynthesis and intraneuronal transport of neurohypophysial hormones; preliminary studies in the rat. Mem Soc Endocrinol 19:337-351

Schlichter DJ, McClure WO (1974) Dynamics of axoplasmic transport in the optic system of the rat. Exp Brain Res 21:83-95

Willard MB, Hulebak KL (1977) The intra-axonal transport of polypeptide H: evidence for a fifth (very slow) group of transported proteins in the retinal ganglion cells of the rabbit. Brain Res 136:289-306

Willard M, Cowan WM, Vagelos PR (1974) The polypeptide composition of intra-axonally transported proteins: evidence for four transport velocities. Proc Natl. Acad Sci 71:2183-2187

Wood PL, Boegman RJ (1975) Increased rate of rapid axonal transport in vitamin E deficient rats. Brain Res 84:325-328

Accepted August 26, 1980 